\title{
Impacts of inhomogeneous landscapes in oasis interior on the oasis self-maintenance mechanism by integrating numerical model with satellite data
}

\author{
X. Meng, S. Lu, T. Zhang, Y. Ao, S. Li, Y. Bao, L. Wen, and S. Luo \\ Key laboratory of Land Surface Process and Climate Change in Cold and Arid Regions, Cold and Arid Regions \\ Environmental and Engineering Research Institute, Chinese Academy of Science, 320 Donggang West Road, \\ 730000 Lanzhou, Gansu, China \\ Correspondence to: X. Meng (mxh@1zb.ac.cn)
}

Received: 31 January 2012 - Published in Hydrol. Earth Syst. Sci. Discuss.: 14 February 2012

Revised: 14 September 2012 - Accepted: 14 September 2012 - Published: 22 October 2012

\begin{abstract}
The impacts of inhomogeneity of the oasis interior on the oasis self-maintenance mechanism are investigated by using the mesoscale model MM5 (the fifth-generation Pennsylvania State University National Center for Atmospheric Research (NCAR) mesoscale model) with satellite observations of land use types, vegetation fraction and surface-layer soil moisture from MODIS (Moderate Resolution Imaging Spectroradiometer) data. Four simulations were performed, among which the CTL (control simulation) and MOD (moderated simulation with parameters replaced by MODIS data) were used to validate the model results; EXP1 (experiment 1) and EXP2 (experiment 2) were designed to study the inhomogeneity of oasis interior. Results show that the changes of oasis heterogeneity influence the surface heat-flux partitioning, which leads to a larger "cold-wet" effect over the oasis. Vertical sections of humidity illustrate the existence of a moisture-inversion level, and the deeper moisture inversion of EXP1 and EXP2 further indicates that the relative homogeneity in the oasis interior helps produce stronger humidity inversion over the oasis, thus limiting evaporation. This is further verified by the analysis of the secondary circulation, which shows that the more homogeneous land surface conditions lead to stronger secondary circulation and less turbulent drafts over the oasis interior, playing a positive role in the oasis self-maintenance and development.
\end{abstract}

\section{Introduction}

The interaction between the atmosphere and the underlying surface is primarily manifested in the heat, moisture, and momentum exchanges between air masses and soil or water (Kukharets and Nalbandyan, 2006). To some extent, the earth's surface is always heterogeneous (Marhrt, 2000; Friedrich and Mölders, 2000). Surface heterogeneity complicates interactions between the atmosphere and the underlying surface, affects moist convection, and systematically produces responses in both local circulation and regional climate (Courault et al., 2007; Reen et al., 2006; Yuan et al., 2008; Yates et al., 2003; Zhang et al., 2010).

In many situations, these locally induced circulations are important in determining mesoscale weather conditions (Wu and Raman, 1997). In the atmospheric boundary layer (ABL), surface heterogeneities affect the microscale to mesoscale circulations through nonlinear processes (Patton et al., 2005; Mahrt et al., 1994; Baidya Roy and Avissar, 2002). Turbulent surface fluxes are strongly affected by the ability of the surface to transform the radiative energy absorbed from the sun and the atmosphere into sensible and latent heat fluxes (Mahrt et al., 1994; Chen et al., 2003). Surface heterogeneities thus induce spatial variability in surface heat fluxes that can create "inland breezes", "oasis effects" and "glacier winds", similar to sea-land breeze systems (Mahfouf et al., 1987; Gao et al., 2004; Lu et al., 2004a; Sun et al., 2007). Such phenomena are known to contribute significantly to energy, water and mass transfer (Bastin and Drobinski, 2006; Meng et al., 2009). 
As unique intrazonal landscapes, oases surrounded by deserts play an important role in arid and semiarid regions of the world. In China, oases account for only $4-5 \%$ of the total area of the arid and semiarid regions, but over $90 \%$ of the population and over $95 \%$ of the social wealth in Northwest China are concentrated in the oases (Han, 2001; Gao et al., 2008). In the last half century, however, the rapid population growth and the overexploitation of water, soil and biological resources have led to drought, salinization, and desertification and consequently have hindered the development of sustainable agriculture, resulting in an urgency to understand oasis-desert interaction and processes (Liu et al., 2006, 2007; Li et al., 2011; Wang et al., 2012).

Studies have investigated the land-atmosphere interactions of the oasis-desert system, indicating that the local circulations driven by the thermal heterogeneity between the oasis and desert are the key factor to maintain the oasis (Chu et al., 2005). Such thermally driven circulations with upward flow over the desert and downward flow over the oasis similar to the sea breezes in the convective boundary layer are referred to as the non-classical mesoscale circulations (Segal and Arritt, 1992) and have been observed in the field (Chen et al., 2005). The updraft over the desert reduces the flow from the desert of low-level hot, dry air into the oasis, and the downdraft increases the atmospheric static stability which in turn reduces the oasis evaporation. Both the upwards and downwards drafts can prevent water loss and soil desertification over the oasis (Chu et al., 2005; Zhang and Huang, 2004; Lu et al., 2004a). Cropland and forest in the oasis can reduce the wind from the desert, limit the evaporation over the oasis and resist sandstorm (Meng et al., 2009). Moreover, the moist air in the lower level over the oasis can be transferred to the higher level over the oasis and the surrounding desert by secondary circulation, producing a moistureinversion (moisture content of the air increases with height) level, reducing evaporation over the oasis, benefiting plant growth in the desert and creating a buffer zone around the oasis (Zhang and Huang, 2004). These processes are referred to as the oasis self-maintenance mechanism. However, the oasis interior is very inhomogeneous, constituted of open water, cropland, urban area, shelterbelt, grassland and desert, especially when the cropland is irrigated during the growing season in Northwest China (Fig. 1). While the basic dynamic and thermodynamic processes over the oasis-desert system are well investigated, a general understanding of the role of inhomogeneous oasis interior on the oasis self-maintenance mechanism remains unknown.

Numerical simulation is an efficient technique to study the mesoscale weather and boundary layer structure over inhomogeneous landscape (Prabha et al., 2007; Kukharets and Nalbandyan, 2006; Chen and Avissar, 1994). Ye and Jia (1995) investigated the impact of wheat over mid-latitude arid areas on mesoscale boundary layer structures and climate. They found that a horizontal pressure gradient associated with mesoscale perturbations in temperature and

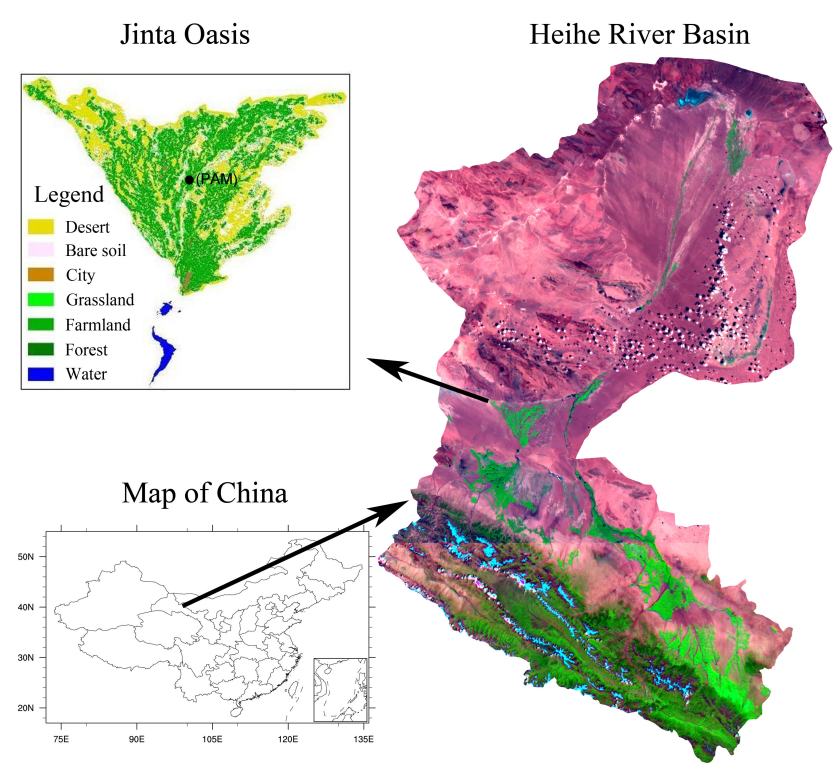

Fig. 1. Location of Jinta Oasis in Heihe River Basin (GeoCover mosaics) and land use map of Jinta Oasis.

humidity was created during the day, which resulted from more water transpired from the vegetation canopy and evaporated from the underlying wet soil. Zhang et al. (2010) designed a number of experiments to examine the effects of changes in heterogeneity patterns on numerical simulations of surface flux exchanges, near-surface meteorological fields, atmospheric planetary boundary layer (PBL) processes, mesoscale circulations, and mesoscale fluxes. They concluded that the increased heterogeneity in the model led to substantial, nonlinear changes in temporal evaluations and spatial patterns of PBL dynamic and thermodynamic processes. Meng et al. (2009) improved meteorological simulations in the Jinta Oasis in Northwest China by involving satellite data, especially to describe the inhomogeneous characteristics over the oasis.

The objective of this paper is to examine the effects of oasis-interior heterogeneity in vegetation and soil moisture on the land-atmosphere exchanges of mass and energy, and the oasis self-maintenance mechanism. Understanding the nature of surface-atmosphere coupling over the oasis-desert system is vitally important for assessing local responses of water and energy transmission in this arid region in China.

The paper is structured as follows. Section 2 briefly presents a description of the study area and the datasets used in this work. Section 3 describes the MM5 model and the experimental design. Section 4 evaluates the simulation results and assesses the impact of the inhomogeneous landscape on the oasis self-maintenance mechanism. The final section summarizes the findings and identifies areas requiring future investigation. 


\section{Study area and datasets}

\subsection{Study area}

The study was conducted at the Jinta Oasis $\left(98^{\circ} 39^{\prime} \mathrm{E}\right.$ $\sim 99^{\circ} 08^{\prime} \mathrm{E}, 39^{\circ} 56^{\prime} \mathrm{N} \sim 40^{\circ} 17^{\prime} \mathrm{N}$ ) in the middle of the Heihe River Basin (Fig. 1) in Northwest China, with a mean annual precipitation of about $59.5 \mathrm{~mm}$ and an annual potential evapotranspiration of $2538.6 \mathrm{~mm}$. The total area is about $165212 \mathrm{~km}^{2}$, mostly composed of farmland, natural grassland and desert-oasis transaction zone (Fig. 1). The Jinta Oasis is very flat, and the elevation variation is only $80 \mathrm{~m}$. There are various soil types including mud soil, tide soil (meadow soil), wind sand soil and typical gray-brown soil at the edge regions (Ma et al., 2002). The soil is continuous and easy to reclaim, so this region is one of the potential land resource developments (by reclaiming or by natural development) and representative areas in China (Chen, 2000). It is also a typical irrigated and agricultural oasis, representative of the inhomogeneous oases in Northwest China.

\subsection{Datasets}

A field experiment was carried out in the summer of 2004 in the Jinta Oasis. Meteorological parameters and surfaceturbulent heat fluxes obtained from the Portable Automated Mesonet (PAM) stations (CSAT3/KH20, Campbell Scientific Inc., Utah) were collected to study the energy and water cycles of the oasis-desert system. The data have been used widely for analyzing the atmospheric boundary layer characteristics and the water-energy budget over the oasis-desert landscapes (Chen et al., 2005). Details of the data can be found in the work of Ao (2006).

Satellite data such as land use types, vegetation fraction cover and surface-layer soil moisture were derived from the Moderate Resolution Imaging Spectroradiometer (MODIS) which gathers data in 36 spectral bands on board the Terra (EOS AM) and Aqua (EOS PM) satellites. Details of the processing and application for the satellite data can be found in the work of Meng et al. (2009).

\section{Numerical simulations}

The nonhydrostatic MM5 (short for the fifth-generation Pennsylvania State University National Center for Atmospheric Research (NCAR) mesoscale model) is a mesoscale, limited-area, terrain-following sigma-coordinate modeling system designed for atmospheric research (Grell et al., 1994). In this study, version 3 coupled with the Noah land surface model (LSM) was used in the simulation. A triple-nested grid system with the same center located at $40.3^{\circ} \mathrm{N}, 98.9^{\circ} \mathrm{E}$ was used. The three systems extend $333 \mathrm{~km}, 120 \mathrm{~km}$, and $61 \mathrm{~km}$ with grid spacing of $9 \mathrm{~km}, 3 \mathrm{~km}$, and $1 \mathrm{~km}$, respectively. The Jinta Oasis is located at the center of the third domain. In the vertical direction, 23 unevenly spaced full sigma levels were defined. MM5 was run with the Medium Range Forecast (MRF) boundary layer scheme, the Kain-Frisch convection scheme, simple ice microphysics and a cloud radiation scheme. The 0000 UTC Global Forecast System (GFS, provided by the National Centers for Environmental Predictions (NCEP)) gridded analysis fields and 6-h interval forecasts, at $1.25^{\circ}$ lat/lon horizontal grid increment, were used to initialize the model and to nudge the boundaries of Grid 1. As a one-way strategy has been selected for the operational chain, Grid 2 used Grid 1 forecasts (at 2-h intervals) and Grid 3 used Grid 2 forecasts (at 1-h intervals) as boundary conditions.

The model was initialized on 4 July 2004 at 12:00 UTC, i.e., 20:00 BT (Beijing Time), and ended on 9 July 2004 at 16:00 UTC, i.e., 00:00 BT on 10 July 2004, during which time the oasis effects were observed in the field experiment (Chen et al., 2005). Following similar simulations for oasisdesert mesoscale circulation in previous works (Chu et al., 2005; Lu et al., 2004a, 2005), the first $30 \mathrm{~h}$ of each simulation were skipped as spin-up time. Hereafter, the simulations from 00:00 BT on 6 July 2004 to 23:00 BT on 9 July 2004 were used for the analysis.

Four simulations were performed in this study. In the first one, all parameters were from MM5 default, which was referred to as CTL. The second experiment was referred to as MOD, in which 1-km-resolution land use types, vegetation fraction and soil moisture at $10-\mathrm{cm}$ depth were replaced by the values derived from MODIS data, with a more closeto-the-truth-of-land-surface condition than CTL. CTL and MOD simulations were used to evaluate the model results. As land use types in MOD include the oasis corridor, open water, farmland and grassland (Fig. 2), it was regarded as realistic simulation for the heterogeneity of the oasis interiors. The other two simulations represented the relatively uniform regions, in which the bare soil and desert patches in the oasis interior in the MOD simulation were replaced by cropland or grassland, showing that the oasis interior was mostly vegetated. The replacement with cropland was referred to as EXP1, and the replacement with grassland was referred to as EXP2. In EXP1 and EXP2, vegetation fraction and soil moisture initials over the substitute area were replaced by the average values of crop and grass, respectively, to represent two possible ways of oasis development (reclaiming farmland and natural development). Land use maps and the distribution of soil moisture at $10-\mathrm{cm}$ depth of the four simulations are shown in Figs. 2 and 3 (vegetation fraction maps omitted). As testing experiments, EXP1 and EXP2 were designed to study the inhomogeneity of the oasis interior; CTL and MOD were used to validate the model results. 

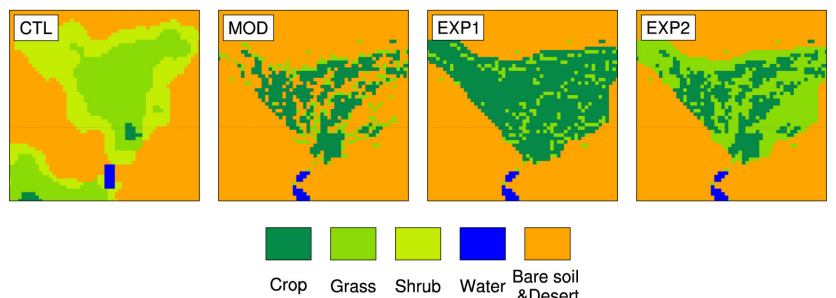

Fig. 2. Land use maps for the third domain of the four simulations.

\section{Results and discussion}

\subsection{Evaluation of simulation results}

Air temperature and specific humidity at $2 \mathrm{~m}$ above ground as well as sensible and latent heat flux outputs from the CTL and MOD simulations were evaluated against the observations (Fig. 4). Bias and root mean square error (RMSE) are shown in Table 1. The MOD experiment produces similar simulations for air temperature and specific humidity at $2 \mathrm{~m}$ above ground and better results for sensible and latent heat fluxes than the CTL, although errors can be seen in both simulations. The time series of the four parameters from the CTL and MOD simulations and the observations are shown in Fig. 4. Both simulations can simulate the diurnal variations of the parameters well. The MOD simulation performs better than the CTL, particularly for sensible and latent heat flux. As a result, the MOD simulation represents a more real and inhomogeneous situation in the follow-up study, while EXP1 and EXP2 indicate relatively uniform land surface conditions.

\subsection{Impacts of inhomogeneity on oasis self-maintaining mechanism}

As was discussed in the introduction, previous studies have considered the mechanisms of oasis self-maintenance in a surrounding desert environment. Most of them focused on the oasis "cold-wet" effects and their driven mesoscale circulations. In general, these studies emphasized the processes from the following aspects: surface heat-flux partitioning, the oasis "cold-wet" effect, the moisture-inversion level and the mesoscale circulation. These mechanisms are explored and discussed in this part.

\subsubsection{Surface heat flux heterogeneity}

According to land surface energy balance, the equations over the oasis and the desert can be expressed as (Holloway and Manabe, 1971; Lu et al., 2004b; Chu et al., 2005)

$R_{\mathrm{n}}^{\mathrm{O}}=H^{\mathrm{O}}+\lambda E^{\mathrm{O}}+G^{\mathrm{O}}$

$R_{\mathrm{n}}^{\mathrm{D}}=H^{\mathrm{D}}+\lambda E^{\mathrm{D}}+G^{\mathrm{D}}$,

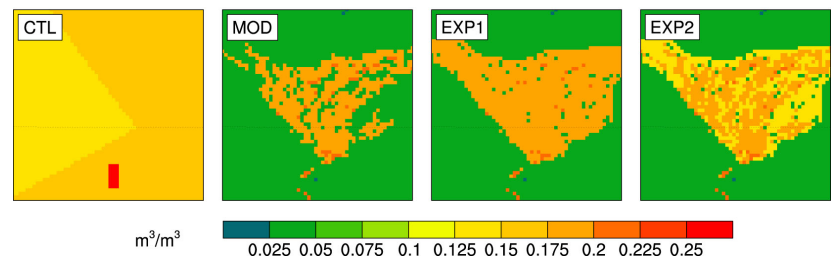

Fig. 3. Distributions of soil moisture at $10-\mathrm{cm}$ depth for the third domain of the four simulations.

where $R_{\mathrm{n}}, H, \lambda E$ and $G$ are the net radiation, sensible heat flux, latent heat flux, and soil heat flux at the oasis (denoted as ${ }^{O}$ ) and the desert (denoted as ${ }^{D}$ ), respectively. The difference of the surface energy balance between the oasis and the desert is represented by

$R_{\mathrm{n}}^{\mathrm{D}}-R_{\mathrm{n}}^{\mathrm{O}}=\left(H^{\mathrm{D}}-H^{\mathrm{O}}\right)+\left(\lambda E^{\mathrm{D}}-\lambda E^{\mathrm{O}}\right)+\left(G^{\mathrm{D}}-G^{\mathrm{O}}\right)$.

According to the analysis of the observations from the Heihe River Basin in China, it was found that the soil heat flux is almost the same in the oasis and in the desert (Kai et al., 1997), i.e., $G^{\mathrm{D}} \approx G^{\mathrm{O}}$, so Eq. (2) can be written as

$R_{\mathrm{n}}^{\mathrm{D}}-R_{\mathrm{n}}^{\mathrm{O}}=\left(H^{\mathrm{D}}-H^{\mathrm{O}}\right)+\left(\lambda E^{\mathrm{D}}-\lambda E^{\mathrm{O}}\right)$.

The characteristics of the surface radiation balance over the desert $R_{\mathrm{n}}^{\mathrm{D}}$ and the oasis $R_{\mathrm{n}}^{\mathrm{O}}$ are analyzed and compared in the HEIFE area by use of the desert and oasis observations (Zhangye station). Shen et al. (1995) found that under a clear sky, the instantaneous fluxes of downward shortwave and longwave radiation reaching the surface and their diurnal variations are nearly the same over the desert and over the oasis. However, due to the surface albedo difference, $R_{\mathrm{n}}^{\mathrm{O}}$ is always larger than $R_{\mathrm{n}}^{\mathrm{D}}$. In summer,

$R_{\mathrm{n}}^{\mathrm{O}}-R_{\mathrm{n}}^{\mathrm{D}} \approx 129.6 \mathrm{~W} \mathrm{~m}^{-2}$.

Kai et al. (1997) found that the latent heat flux is smaller over the desert $\left(67 \mathrm{~W} \mathrm{~m}^{-2}\right)$ than over the oasis $\left(634 \mathrm{~W} \mathrm{~m}^{-2}\right)$ in the HEIFE region:

$\lambda E^{\mathrm{O}}-\lambda E^{\mathrm{D}} \geq 530 \mathrm{~W} \mathrm{~m}{ }^{-2}$.

Combining Eqs. (3), (4) and (5), the difference of sensible heat flux between the oasis and the desert can be expressed as

$H^{\mathrm{O}}-H^{\mathrm{D}} \leq-400 \mathrm{~W} \mathrm{~m}^{-2}$.

The differential sensible heat fluxes over the oasis and the surrounding desert regions drive the secondary circulation with the downdraft flow over the oasis and the updraft flow over the desert. Moreover, latent heat consumption over the oasis results in evident lower temperature and higher humidity over the oasis, i.e., the "cold-wet" effect. 

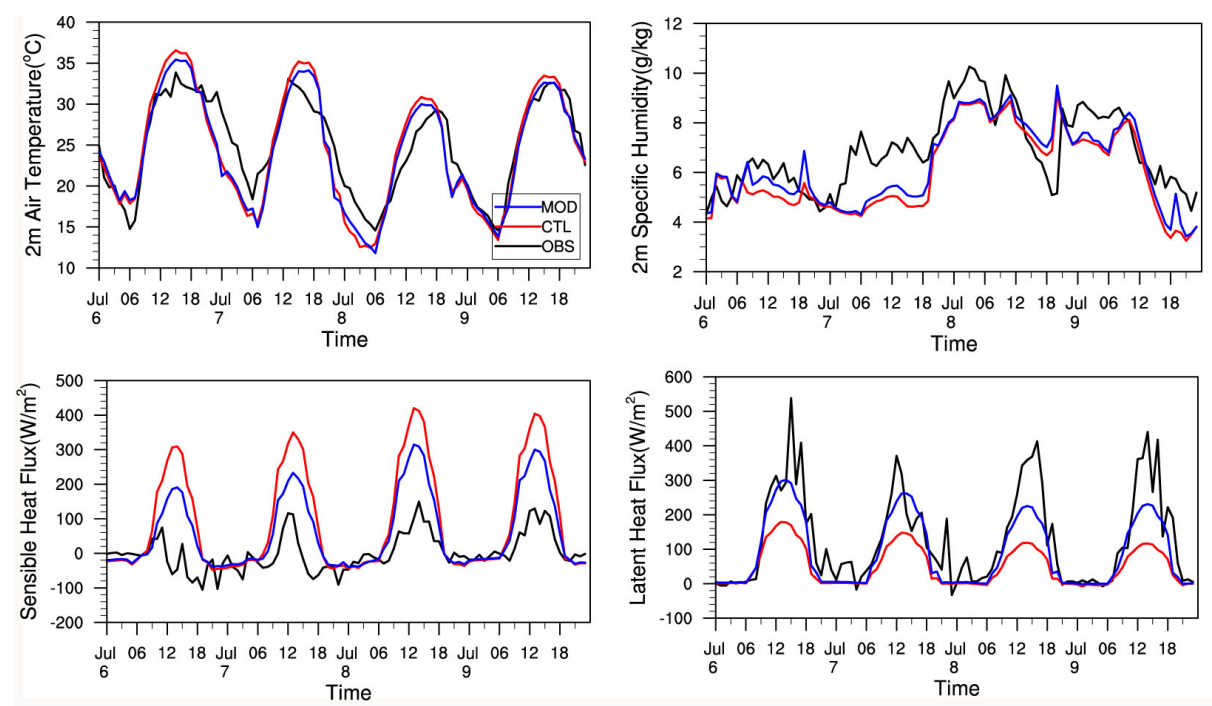

Fig. 4. Observations of air temperature and specific humidity at $2 \mathrm{~m}$ above ground as well as sensible and latent heat fluxes of the CTL versus the MOD simulations.

Table 1. Statistics of air temperature and specific humidity at $2 \mathrm{~m}$ above ground as well as sensible and latent heat fluxes between the CTL and MOD simulations and the observations.

\begin{tabular}{|c|c|c|c|c|c|c|c|c|}
\hline \multirow[t]{2}{*}{ Statistics } & \multicolumn{2}{|c|}{$\begin{array}{c}\text { Air temperature } \\
\left({ }^{\circ} \mathrm{C}\right)\end{array}$} & \multicolumn{2}{|c|}{$\begin{array}{l}\text { Specific humidity } \\
\left(\mathrm{g} \mathrm{kg}^{-1}\right) \quad\left(\mathrm{W} \mathrm{m}^{-2}\right)\end{array}$} & \multicolumn{2}{|c|}{$\begin{array}{l}\text { Sensible heat flux } \\
\left(\mathrm{W} \mathrm{m}^{-2}\right)\end{array}$} & \multicolumn{2}{|c|}{ Latent heat flux } \\
\hline & CTL & MOD & CTL & MOD & CTL & MOD & CTL & MOD \\
\hline Bias & -0.79 & -0.34 & -0.861 & -0.585 & 93.1 & 58.5 & -78.8 & -38.3 \\
\hline RMSE & 3.03 & 2.79 & 1.373 & 1.234 & 152.8 & 98.4 & 120.1 & 76.6 \\
\hline
\end{tabular}

Figure 5 shows the difference of sensible and latent heat flux between the oasis and the desert in a time series. The difference was calculated by subtracting the average heat flux over the desert from the average heat flux over the oasis. It indicates that big differences between the oasis and the desert in sensible and latent heat flux occurred during the daytime (06:00 to 18:00 BT). For sensible heat flux, the maximum difference happened around 13:00 BT with a value varying from $-220 \sim-150 \mathrm{~W} \mathrm{~m}^{-2}$ on different days. Latent heat flux is similar to sensible heat, except that the maximums of latent heat flux are between $120 \sim 180 \mathrm{~W} \mathrm{~m}^{-2}$. Comparing EXP1 and EXP2 with the MOD simulation, the changes in oasis heterogeneity affect the surface heat flux partitioning, but the influence of EXP1 is larger than that of EXP2.

MM5 uses a global land use map to set the surface physical parameters to model the soil-atmosphere processes. In the EXP1 and EXP2 simulations, cropland and grassland are used to specify the inhomogeneity, and parameters including moisture availability and thermal inertia in MM5 show greater differences between the two land use types than other parameters such as albedo and emissivity. In summer, the moisture availability was $25 \%$ for cropland and $15 \%$ for grassland, and the thermal inertia was $0.04 \mathrm{cal} \mathrm{cm}^{-2} \mathrm{k}^{-1} \mathrm{~s}^{-1 / 2}$ for cropland and $0.03 \mathrm{cal} \mathrm{cm}^{-2} \mathrm{k}^{-1} \mathrm{~s}^{-1 / 2}$ for grassland, which resulted in the different impacts on the surface heat-flux partitioning and the oasis self-maintenance mechanism.

\subsubsection{Oasis "cold-wet" effect}

Figures 6 and 7 show the difference in air temperature and specific humidity at $2 \mathrm{~m}$ above ground between the oasis and the desert from the MOD, EXP1, and EXP2 simulations in a time series. The difference is calculated by subtracting average values over the desert from average values over the oasis. All simulations show negative differences for temperature and positive differences for humidity between the oasis and the desert during the daytime, indicating that the oasis is a "wet-cold" island in the daytime. Among the three simulations, EXP1 produces the highest temperature and humidity differences, while values in EXP2 are close to MOD, resulting from the energy heat flux partitioning due to different land use-related parameters.

The surface energy heterogeneity and "cold-wet" effect occur during the daytime (06:00 to 18:00 BT, shown in Fig. 5), and the oasis effect and its self-protecting mechanism are the most evident in the afternoon (i.e., around 

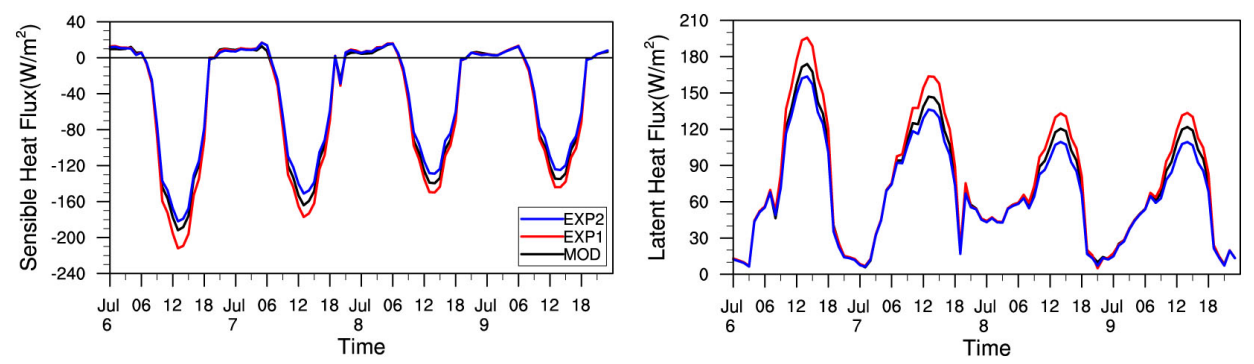

Fig. 5. The difference of sensible and latent heat fluxes between the oasis and the desert in a time series from the MOD, EXP1 and EXP2 simulations (the difference was calculated by subtracting the average heat flux over the desert from the average heat flux over the oasis).

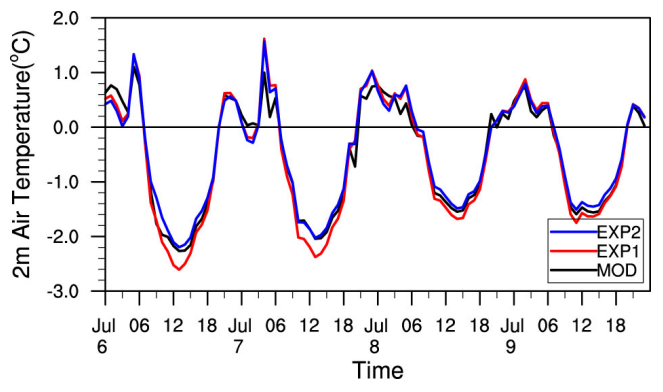

Fig. 6. The differences of air temperature at $2 \mathrm{~m}$ above ground between the oasis and the desert in a time series from the MOD, EXP1 and EXP2 simulations (the difference was calculated by subtracting the average air temperature over the desert from the average air temperature over the oasis).

13:00 BT) (Chu et al., 2005; Chen et al., 2005). Distributions of air temperature at $2 \mathrm{~m}$ above ground and its differences between the MOD, EXP1 and EXP2 simulations at 13:00 BT on 6 July 2004 are shown in Fig. 8. Maximum air temperatures at $2 \mathrm{~m}$ above ground are around $36.5^{\circ} \mathrm{C}$ in the north of the oasis for all three simulations, while the area of maximums in MOD is slightly larger than in EXP1 and EXP2. The minimum temperature at $2 \mathrm{~m}$ above ground is around $32^{\circ} \mathrm{C}$ (open water excluded) in the south of the oasis, with the largest lowtemperature region produced by EXP1. According to land use types shown in Fig. 2, maximums in all simulations are around bare soil and desert. Except for over the lakes, minimums in all simulations occur over densely vegetated regions. Furthermore, minimums occur in the west of the oasis in the EXP1 simulation, while they are distributed along the vegetation in the MOD and EXP2 simulations. Considering the temperature changes, air temperature at $2 \mathrm{~m}$ above ground over the oasis decreases by about $2.5^{\circ} \mathrm{C}$ in EXP1 compared with MOD, while it decreases by about $1.5^{\circ} \mathrm{C}$ in EXP2.

As to the "cold island" effect, the differences of average daily air temperature at $2 \mathrm{~m}$ above ground between the oasis and the desert (oasis minus desert) during the daytime for the three simulations are shown in Table 2. It shows that the "cold island" effect of the oasis is increased in EXP1, making the oasis $0.08^{\circ} \mathrm{C}$ colder than that in the MOD simulation,
Table 2. Differences of averaged air temperature at $2 \mathrm{~m}$ above ground between the oasis and the desert (oasis minus desert) during the time period from 06:00 to 18:00 BT for the MOD, EXP1 and EXP2 simulations $\left({ }^{\circ} \mathrm{C}\right)$.

\begin{tabular}{lrrrr}
\hline & 6 July & 7 July & 8 July & 9 July \\
\hline MOD & -1.36 & -1.21 & -0.89 & -0.97 \\
EXP1 & -1.47 & -1.35 & -0.92 & -1.01 \\
EXP2 & -1.19 & -1.14 & -0.77 & -0.88 \\
\hline
\end{tabular}

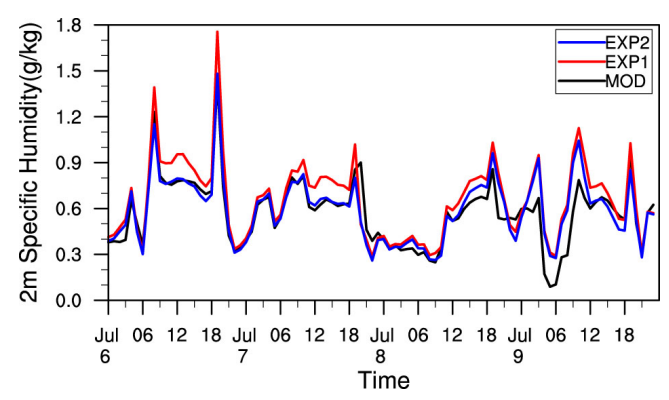

Fig. 7. The differences of specific humidity at $2 \mathrm{~m}$ above ground between the oasis and the desert in a time series from the MOD, EXP1 and EXP2 simulations (the difference was calculated by subtracting the average specific humidity over the desert from the average specific humidity over the oasis).

which is about $7 \%$ of the MOD value, while it is reduced in EXP2, making the oasis $0.11^{\circ} \mathrm{C}$ warmer than that in MOD.

Specific humidity at $2 \mathrm{~m}$ above ground and the differences between the MOD, EXP1 and EXP2 simulations at 13:00 BT on 6 July 2004 are shown in Fig. 9. All simulations present the oasis as a "wet island". The driest region is over the desert and the wettest is over the oasis. Similar to air temperature at $2 \mathrm{~m}$ above ground, specific humidity at $2 \mathrm{~m}$ above ground is distributed along the vegetation in the oasis in the MOD simulation, but concentrations and maximums occur in the western center in the EXP1 and EXP2 simulations, with greater humidity (wet island) in EXP1 than in EXP2. Compared with the MOD simulation, specific humidity at $2 \mathrm{~m}$ above ground over the oasis increases by about $1.0 \mathrm{~g} \mathrm{~kg}^{-1}$ in EXP1, while it increases by about $0.5 \mathrm{~g} \mathrm{~kg}^{-1}$ in EXP2. 
Table 3. Differences of averaged specific humidity at $2 \mathrm{~m}$ above ground between the oasis and the desert (oasis minus desert) during the time period from 06:00 to 18:00 BT for the MOD, EXP1 and EXP2 simulations $\left(\mathrm{g} \mathrm{kg}^{-1}\right)$.

\begin{tabular}{lrrrr}
\hline & 6 July & 7 July & 8 July & 9 July \\
\hline MOD & 0.747 & 0.65 & 0.462 & 0.503 \\
EXP1 & 0.835 & 0.754 & 0.541 & 0.683 \\
EXP2 & 0.721 & 0.659 & 0.49 & 0.612 \\
\hline
\end{tabular}
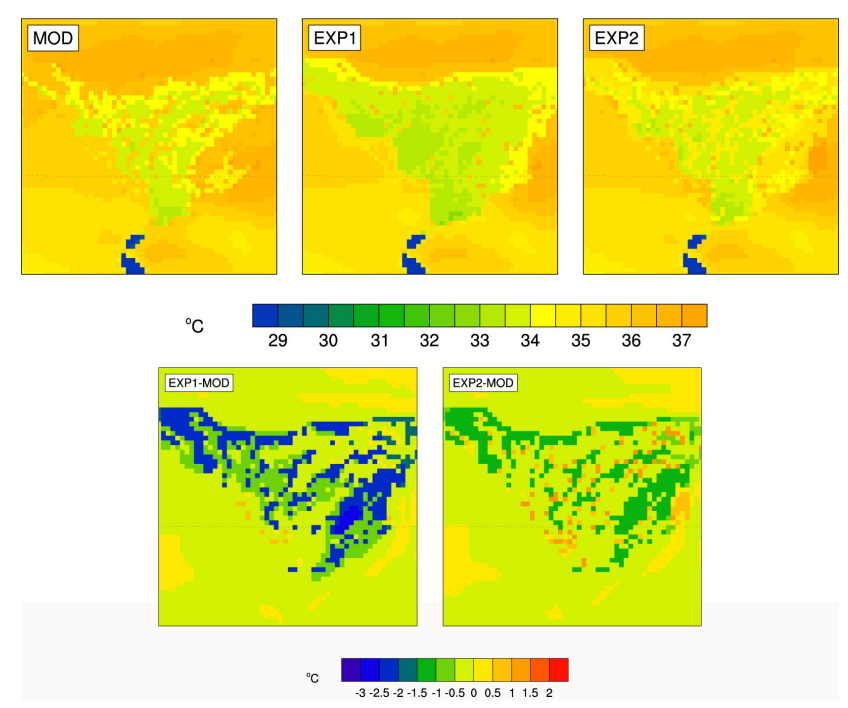

Fig. 8. Air temperature at $2 \mathrm{~m}$ above ground and its differences between the MOD and the EXP1 and EXP2 simulations at 13:00 BT, 6 July 2004.

The differences of average daily specific humidity at $2 \mathrm{~m}$ above ground between the oasis and the desert (oasis minus desert) during the day for the three simulations are shown in Table 3. Both EXP1 and EXP2 display a stronger "wet island" effect than the MOD simulation (on average $19 \%$ more in EXP1 and $6 \%$ more in EXP2 than in MOD).

\subsubsection{Moisture-inversion level}

As was discussed above, the moisture-inversion level is one of the protecting mechanisms to reduce the oasis evaporation. The vertical latitudinal section of specific humidity in the middle of the oasis is shown in Fig. 10 (from $98.74^{\circ} \mathrm{E}$ to $99.23^{\circ} \mathrm{E}$ is mainly oasis). All simulations present the oasis as a "wet island", with a maximum contour value of $5.0 \mathrm{~g} \mathrm{~kg}^{-1}$ for MOD, $5.4 \mathrm{~g} \mathrm{~kg}^{-1}$ for EXP1 and $5.2 \mathrm{~g} \mathrm{~kg}^{-1}$ for EXP2. The moisture in the level from surface to $770 \mathrm{hPa}$ over the oasis is higher in EXP1 and EXP2 than in MOD. All simulations produce deep humidity inversions above the $700 \mathrm{hPa}$ layer, limiting water loss through evaporation from the oasis. The moisture-inversion level is the greatest in EXP1, and it is greater in EXP2 than in MOD. Therefore, both EXP1

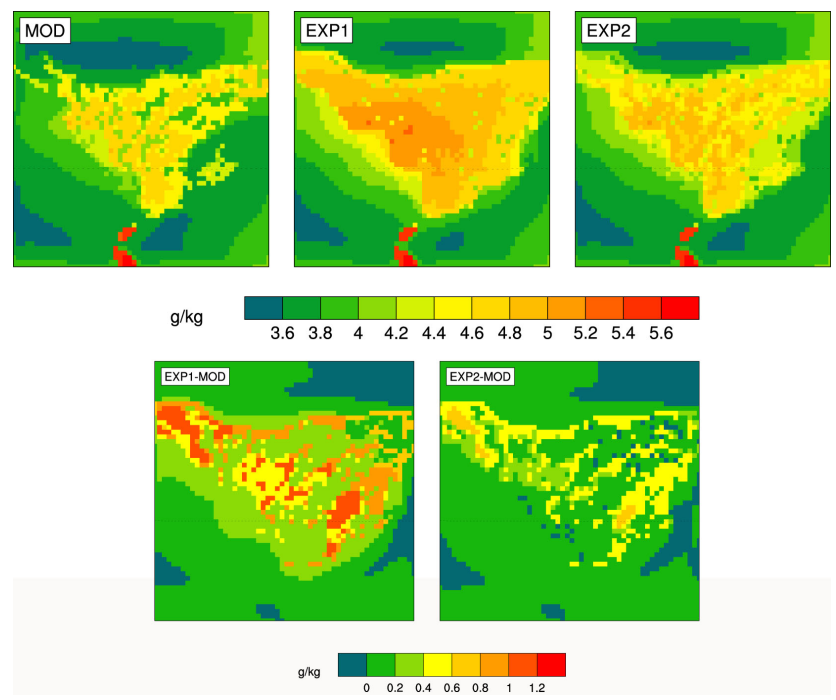

Fig. 9. Specific humidity at $2 \mathrm{~m}$ above ground and its differences between the MOD and the EXP1 and EXP2 simulations at 13:00 BT, 6 July 2004.

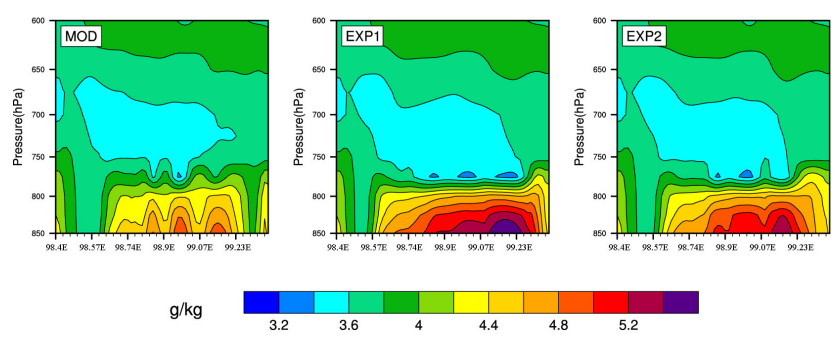

Fig. 10. Vertical latitudinal section of specific humidity at $2 \mathrm{~m}$ above ground $\left(\mathrm{g} \mathrm{kg}^{-1}\right)$ from the MOD, EXP1 and EXP2 simulations at 13:00 BT, 6 July 2004.

and EXP2 have a stronger "wet island" effect and greater moisture-inversion level compared with the MOD simulation, showing the positive role of the oasis self-maintenance mechanism.

\subsubsection{Mesoscale circulation}

Figure 11 displays the modeled horizontal winds and air temperature at 850 and $750 \mathrm{hPa}$ in the three simulations at 13:00 BT, 6 July 2004. All simulations show that the oasis is a "cold island" at these two levels. The horizontal winds are divergent at both levels in all three simulations, and are affected by the background winds at $750 \mathrm{hPa}$. Comparing EXP1 and EXP2 with the MOD simulation, in general divergence occurs, but slight convergence can be seen over the bare soil and desert patches in the oasis interior in the MOD simulation. Divergence over the oasis in EXP1 and EXP2 are shown to be less affected due to the relative homogeneity of the oasis interior. Furthermore, divergent wind speeds in EXP1 and EXP2 are greater than in MOD and are 


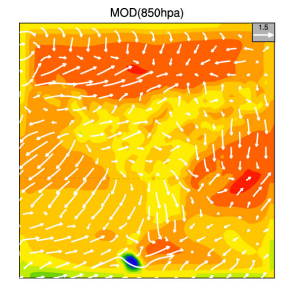

MOD(750hpa)

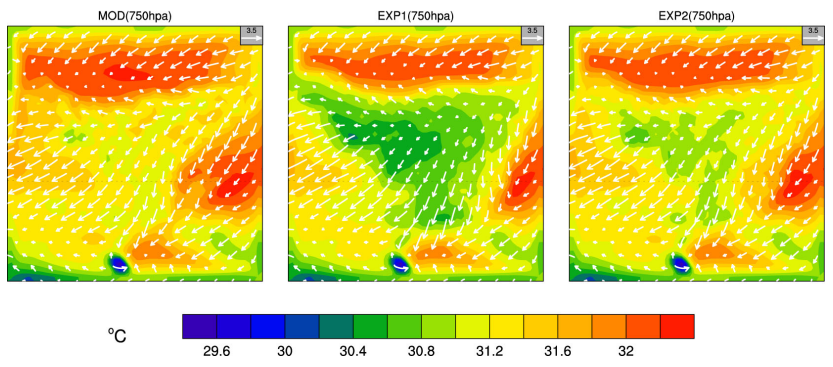

Fig. 11. Simulated horizontal winds $\left(\mathrm{m} \mathrm{s}^{-1}\right)$ and air temperature $\left({ }^{\circ} \mathrm{C}\right)$ at $850 \mathrm{hPa}$ from the MOD, EXP1 and EXP2 simulations at 13:00 BT, 6 July 2004.

reduced over the oasis interior due to inhomogeneity in the MOD simulation. Comparing EXP1 with EXP2, the divergent wind speeds in EXP2 are smaller than in EXP1 over the oasis interior.

Figure 12 displays the vertical latitudinal section of the vertical velocity at 13:00 BT, 6 July 2004, for the three simulations. Positive values indicate sinking motion. All simulations show that downdraft airflows are produced over the oasis, while updrafts exist at the edge of the oasis (i.e., around $98.74^{\circ} \mathrm{E}$ and $99.15^{\circ} \mathrm{E}$ in $\mathrm{MOD}, 98.74^{\circ} \mathrm{E}$ and $99.23^{\circ} \mathrm{E}$ in EXP1 and EXP2). From 750 to $600 \mathrm{hPa}$, EXP1 shows a stronger and wider downward motion than EXP2 and MOD, and the downdrafts in EXP1 are stronger than in MOD as well. In the lower levels from 850 to $750 \mathrm{hPa}$, airflow has more turbulences in the MOD simulation but only decreases over the oasis interior in EXP1 and slightly fluctuates in EXP2, which is consistent with characteristics of the horizontal winds shown in Fig. 11.

As was discussed in the introduction, the air flow diverges from the oasis to the desert, produces downdrafts over the oasis, and then converges around the oasis-desert transition to form updrafts. During this process, it holds water over the oasis and prevents it from flowing into the desert. This mechanism has a positive effect on protecting the oasis. Comparisons among the three simulations show that the inhomogeneity of the MOD simulation produces slightly less divergence than EXP1 and EXP2. The interactions of divergence and convergence (Fig. 11) and updrafts and downdrafts (Fig. 12) over the oasis in the MOD case can result in the instability of the oasis interior and strengthen the turbulence and evaporation over the oasis. Once the turbulence is strong enough to break up the secondary circulation driven by the thermal heterogeneity between the oasis and the desert, water and heat exchange between the oasis and the desert will

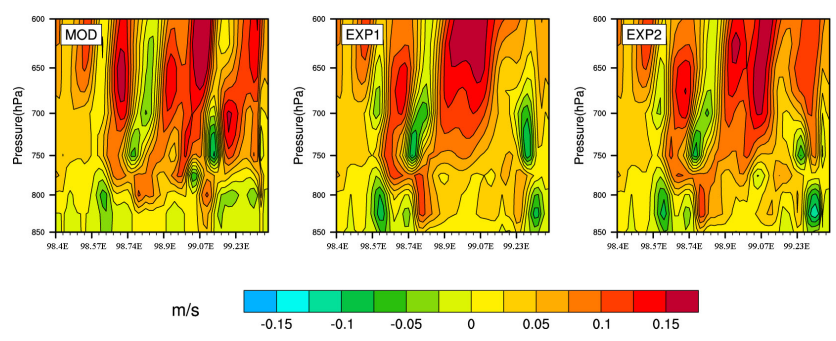

Fig. 12. Vertical latitudinal section of vertical velocity $\left(\mathrm{m} \mathrm{s}^{-1}\right)$ from the MOD, EXP1 and EXP2 simulations at 13:00 BT, 6 July 2004.

be enhanced and water vapor over the oasis will flow into the surrounding desert. It will lead to a drier oasis and may even drive the oasis into water deficiency and soil desertification (Meng et al., 2009).

\section{Conclusions}

The influence of inhomogeneity of the oasis interior on the oasis self-maintenance mechanism was investigated by using the mesoscale model MM5 with satellite-derived land use type, vegetation fraction and surface-layer soil moisture from MODIS data. Four simulations were performed, of which CTL (control simulation) and MOD (moderated simulation with parameters replaced by MODIS data) were used to validate the model results. It was found that the input of the MODIS-derived parameters can produce a better simulation. EXP1 and EXP2 were designed to study the inhomogeneity of oasis interior with inhomogeneous landscape, and its related parameters were replaced by those of crop in EXP1 and those of grassland in EXP2. The results indicate that the MOD simulation can produce a better simulation than the CTL. EXP1 and EXP2 were designed to present the future development of oases, i.e., EXP1 reduces the inhomogeneity by farmland reclaiming while EXP2 that by natural development. With more realistic and possible conditions, results of MOD, EXP1 and EXP2 were compared to investigate the influence of heterogeneity on the oasis self-maintenance mechanism.

Surface heat flux heterogeneity in the simulations was explored first. Significant differences between the oasis and the desert in sensible and latent heat flux occurred during the daytime, resulting in a "cold island" of the oasis. For sensible heat flux, the maximum difference occurred around midday with the value varying between $-220 \sim-150 \mathrm{~W} \mathrm{~m}^{-2}$ on different days. The maximums of the latent heat fluxes are between $120 \sim 180 \mathrm{~W} \mathrm{~m}^{-2}$. Comparisons among the simulations show that the changes of oasis heterogeneity influence the surface heat-flux partitioning, but it is larger in EXP1 than in EXP2.

The water and energy cycles are the most important factors for the oasis self-protecting. All the simulations show negative differences for temperature and positive differences 
for humidity during the daytime, indicating that the oasis is a "wet-cold" island in the daytime. Among the three simulations, EXP1 produces the strongest "cold-wet" island, while EXP2 has a stronger "wet" island but similar "cold" island as MOD. Vertical sections of humidity illustrate the existence of a moisture-inversion level. The deeper moisture inversion in EXP1 and EXP2 further indicates that the relative homogeneity in the oasis interior promotes stronger humidity inversion over the oasis, limiting evaporation over the oasis.

The more homogeneous land surface conditions make the secondary circulation stronger, and the inhomogeneity creates both the updrafts and the downdrafts over the oasis interior. The stronger circulations in EXP1 and EXP2 are favorable for the oasis maintenance and development, while the interacting mechanism of divergence and convergence in MOD can result in the instability over the oasis interior and strengthen the turbulence and evaporation over the oasis. Furthermore, the turbulence will decrease the "cold island" effect and then reduce the dynamic driver of the oasis-desert secondary circulation. Once the oasis interior is inhomogeneous enough, the secondary circulation is easy to break up, and the water and heat exchange between the oasis and the desert will be enhanced. It may allow water vapor over the oases to flow into the surrounding deserts, resulting in dryer oases or even driving the oases into water deficiency and soil desertification.

This study is an attempt to explore the oasis selfmaintenance mechanism and its response to the inhomogeneity of the oasis interior. The response seems to be affirmative. However, further investigations are needed in order to fully understand whether the strong impact of inhomogeneity on the oasis self-maintenance mechanism seen in this study is related to particular specification of land use types (i.e., the two possible ways of reclaiming) and affected by the initial conditions and model sensitivity. According to the evaluation of the model results, replacement of parameters with satellite observations seems to produce better simulations. However, it is worth investigating why errors are present in the simulations for surface heat fluxes. Is it influenced by parameters such as roughness length and moisture availability, which were considered to affect the simulation for surface fluxes in MM5 (Oncley and Dudhia, 1995), or because even in a perfect LSM, inadequate initial soil moisture fields will lead to major biases in the partitioning of surface energy and have a long-lasting effect on the model behavior (Chen and Dudhia, 2001), or both? Further investigations are needed to obtain more robust conclusions and to better address these questions.

Acknowledgements. This work was under the auspices of the National Basic Research Program of China (973 Program, No. 2010CB950503), the Chinese National Science Foundation Programs (No. 40905006, 41005011 and 40805002) and the West Light Foundation of Chinese Academy of Sciences (No. 29Y028681). MM5 is made publicly available and supported by the Mesoscale and Microscale Meteorology division at the National Center for Atmospheric Research. Thanks are owed for their dedication and hard work. The EOS/MODIS satellite data used in this study were acquired from NASA's Earth Science Enterprise. The MODIS Science Teams are gratefully acknowledged. We also want to express our thanks to the people who obtained the observations in the "Jinta experiment".

Edited by: L. Wang

\section{References}

Ao, Y.: The study of land surface processes and climate effect over the desert-oasis, PhD Thesis, Cold and Arid Reg. Environ. and Eng. Res. Inst., Chin. Acad. of Sci., Lanzhou, China., 39-53, 2006.

Baidya Roy, S. and Avissar, R.: Impact of land use/land cover change on regional hydrometeorology in Amazonia, J. Geophys. Res., 107, 8037, doi:10.1029/2000jd000266, 2002.

Bastin, S. and Drobinski, P.: Sea-breeze-induced mass transport over complex terrain in south-eastern France: A case-study, Q. J. Roy. Meteor. Soc., 132, 405-423, 2006.

Chen, F. and Avissar, R.: The impact of land-surface wetness heterogeneity on mesoscale heat fluxes, J. Appl. Meteorol., 33, 13231340, 1994.

Chen, F. and Dudhia, J.: Coupling an advanced land surface hydrology model with the Penn State-NCAR MM5 modeling system, Part I: Model implementation and sensitivity, Mon. Weather Rev., 129, 569-585, 2001.

Chen, F., Yates, D. N., Nagai, H., LeMone, M. A., Ikeda, K., and Grossman, R. L.: Land surface heterogeneity in the Cooperative Atmosphere Surface Exchange Study (CASES0-97), Part I: Comparing modeled surface flux maps with surface-flux tower and aircraft measurements, J. Hydrometeorol., 4, 196-218, 2003.

Chen, S., Lu, S., Ao, Y., Zhang, Y., Hu, Z., and Wei, Z.: Preliminary analyses on ground level wind field of second circulation in Jinta oasis and desert in summer, Plateau Meteorol., 24, 534539, 2005.

Chen, W.: Gansu Yearbook-2000, China Stat Press, Beijing, 299301, 2000.

Chu, P. C., Lu, S., and Chen, Y.: A numerical modeling study on desert oasis self-supporting mechanisms, J. Hydrol., 312, 256276, 2005.

Courault, D., Drobinski, P., Brunet, Y., Lacarrere, P., and Talbot, C.: Impact of surface heterogeneity on a buoyancy-driven convective boundary layer in light winds, Bound.-Lay. Meteorol., 124, 383403, 2007.

Friedrich, K. and Mölders, N.: On the influence of surface heterogeneity on latent heat fluxes and stratus properties, Atmos. Res., 54, 59-85, 2000.

Gao, Y., Lu, S., and Chen, Y.: Numerical simulation of the critical scale of oasis maintenance and development in the arid regions of northwest China, Adv. Atmos. Sci., 21, 113-124, 2004.

Gao, Y., Chen, F., Barlage, M., Liu, W., Cheng, G., Li, X., Yu, Y., Ran, Y., Li, H., Peng, H., and Ma, M.: Enhancement of land surface information and its impact on atmospheric modeling in the Heihe River Basin, northwest China, J. Geophys. Res., 113, D20S90, doi:10.1029/2008jd010359, 2008. 
Grell, G., Dudhia, J., and Stauffer, D.: A description of the fifth generation Penn State/NCAR Mesoscale Model (MM5), NCAR/TN-398CSTR, Nat. Cent. for Atmos. Res., Boulder, Colorado, p. 117, 1994.

Han, D.: Artificial Oases of Xinjiang (in Chinese), Chin. Environ. Sci. Press, Beijing, 21-32, 2001.

Holloway, J. and Manabe, S.: Simulation of climate by a global general circulation model. Part-1. Hydrologic cycle and heat balance, Mon. Weather Rev., 99, 325-370, 1971.

Kai, K., Matsuda, M., and Sato, R.: Oasis effect observed at Zhangye Oasis in the Hexi Corridor, China, J. Meteorol. Soc. Jpn., 75, 1171-1178, 1997.

Kukharets, V. and Nalbandyan, H.: Temperature fluctuations in the atmospheric surface layer over the thermally inhomogeneous underlying surface, Izvestiya Atmos. Ocean. Phys., 42, 456-462, 2006.

Li, W., Lü, S., Fu, S., Meng, X., and Nnamchi, H.: Numerical simulation of fluxes generated by inhomogeneities of the underlying surface over the Jinta Oasis in Northwestern China, Adv. Atmos. Sci., 28, 887-906, 2011.

Liu, S., Jiang, H., Deng, Y., Ma, M., Pan, Y., Jiang, H., Lin, H., Liang, F., Liu, H., and Wang, J.: Numerical simulation of the interaction between forest ecological system and atmospheric boundary layer, Front. Forest. China, 1, 1-11, 2006.

Liu, S., Liu, H., Hu, Y., Zhang, C., Liang, F., and Wang, J.: Numerical simulations of land surface physical processes and land-atmosphere interactions over oasis-desert/Gobi region, Sci. China Ser. D, 50, 290-295, 2007.

Lu, S., An, X., and Chen, Y.: Simulation of oasis breeze circulation in the arid region of the Northwestern China, Sci. China Ser. D, 47, 101-107, 2004.

Lu, S., Chen, Y., Chen, S., and Zhu, B.: Preliminary study of thermodynamic of oasis-desert interaction in Hexi area in summer, Plateau Meteorol., 23, 127-131, 2004 (in Chinese).

Lu, S., Shang, L., Liang, L., and Luo, S.: Numerical simulation of microclimate effect in Jinta oasis, Plateau Meteorol., 24, 649655, 2005 (in Chinese).

Ma, M., Cao, Y., and Cheng, G.: Study on the oasis corridor landscape in the arid regions based on RS and GIS methods - Application of Jinta oasis, China, J. Environ. Sci., 15, 193-198, 2002.

Mahfouf, J. F., Richard, E., and Mascart, P.: The influence of soil and vegetation on the development of mesoscale circulations, J. Clim. Appl. Meteorol., 26, 1483-1495, 1987.

Mahrt, L.: Surface heterogeneity and vertical structure of the boundary layer, Bound.-Lay. Meteorol., 96, 33-62, 2000.

Mahrt, L., Macpherson, J. I., and Desjardins, R.: Observations of fluxes over heterogeneous surfaces, Bound.-Lay. Meteorol., 67, 345-367, 1994.

Meng, X., Lü, S., Zhang, T., Guo, J., Gao, Y., Bao, Y., Wen, L., Luo, S., and Liu, Y.: Numerical simulations of the atmospheric and land conditions over the Jinta oasis in northwestern China with satellite-derived land surface parameters, J. Geophys. Res., 114, D06114, doi:10.1029/2008jd010360, 2009.
Oncley, S. P. and Dudhia, J.: Evaluation of surface fluxes from mm 5 using observations, Mon. Weather Rev., 123, 3344-3357, 1995.

Patton, E. G., Sullivan, P. P., and Moeng, C.-H.: The influence of idealized heterogeneity on wet and dry planetary boundary layers coupled to the land surface, J. Atmos. Sci., 62, 2078-2097, 2005.

Prabha, T., Karipot, A., and Binford, M.: Characteristics of secondary circulations over an inhomogeneous surface simulated with large-eddy simulation, Bound.-Lay. Meteorol., 123, 239261, 2007.

Reen, B., Stauffer, D., Davis, K., and Desai, A.: A case study on the effects of heterogeneous soil moisture on mesoscale boundarylayer structure in the Southern Great Plains, U.S.A., Part II: Mesoscale Modelling, Bound.-Lay. Meteorol., 120, 275-314, 2006.

Segal, M. and Arritt, R. W.: Non-classical circulations caused by surface sensible heat-flux gradients, B. Am. Meteorol. Soc., 73, 1593-1604, 1992.

Shen, Z., Tsukamoto, O., and Zou, J.: The radiative energy budget on the ground surface over desert and oasis in the HEIFE area, J. Meteorol. Soc. Jpn., 73, 1301-1307, 1995.

Sun, F., Ma, Y., Li, M., Ma, W., Tian, H., and Metzger, S.: Boundary layer effects above a Himalayan valley near Mount Everest, Geophys. Res. Lett., 34, L08808, doi:10.1029/2007g1029484, 2007.

Wang, L., D’Odorico, P., Evans, J. P., Eldridge, D. J., McCabe, M. F., Caylor, K. K., and King, E. G.: Dryland ecohydrology and climate change: critical issues and technical advances, Hydrol. Earth Syst. Sci., 16, 2585-2603, doi:10.5194/hess-16-25852012, 2012.

Wu, Y. and Raman, S.: Effect of land-use pattern on the development of low-level jets, J. Appl. Meteorol., 36, 573-590, 1997.

Yates, D. N., Chen, F., and Nagai, H.: Land surface heterogeneity in the Cooperative Atmosphere Surface Exchange Study (CASES97), Part II: Analysis of spatial heterogeneity and its scaling, J. Hydrometeorol., 4, 219-234, 2003.

Ye, Z. and Jia, X.: Mesoscale vegetation-breeze circulation and their impact on boundary layer structures at Night, Adv. Atmos. Sci., 12, 29-46, 1995.

Yuan, X., Xie, Z., Zheng, J., Tian, X., and Yang, Z.: Effects of water table dynamics on regional climate: a case study over East Asian Monsoon Area, J. Geophys. Res., 113, D21112, doi:10.1029/2008JD010180, 2008.

Zhang, N., Williams, Q., and Liu, H.: Effects of land-surface heterogeneity on numerical simulations of mesoscale atmospheric boundary layer processes, Theor. Appl. Climatol., 102, 307-317, 2010.

Zhang, Q. and Huang, R.: Water vapor exchange between soil and atmosphere over a gobi surface near an oasis in the summer, J. Appl. Meteorol., 43, 1917-1928, 2004. 